\title{
Signal transduction-dependent small regulatory RNA is involved in glutamate metabolism of the human pathogen Bordetella pertussis
}

\author{
KRISTINA KEIDEL, ${ }^{1}$ FABIAN AMMAN,${ }^{2,3}$ ILONA BIBOVA, ${ }^{1}$ JAKUB DRZMISEK, ${ }^{1}$ VLADIMIR BENES, ${ }^{4}$ \\ DAVID HOT, ${ }^{5}$ and BRANISLAV VECEREK ${ }^{1}$ \\ ${ }^{1}$ Institute of Microbiology v.v.i., Laboratory of post-transcriptional control of gene expression, 14220 Prague, Czech Republic \\ ${ }^{2}$ Institute for Theoretical Chemistry, University of Vienna, A-1090 Vienna, Austria \\ ${ }^{3}$ Department of Chromosome Biology of the University of Vienna, A-1030 Vienna, Austria \\ ${ }^{4}$ Genomics Core Facility, European Molecular Biology Laboratory, 69117 Heidelberg, Germany \\ ${ }^{5}$ Université de Lille, CNRS, Inserm, CHU Lille, Institut Pasteur de Lille, U1019 - UMR8204 - CIIL - Center for Infection and Immunity of Lille, \\ F-59000 Lille, France
}

\begin{abstract}
Bordetella pertussis is the causative agent of human whooping cough, a highly contagious respiratory disease which despite vaccination programs remains the major cause of infant morbidity and mortality. The requirement of the RNA chaperone $\mathrm{Hfq}$ for virulence of $\mathrm{B}$. pertussis suggested that $\mathrm{Hfq}$-dependent small regulatory RNAs are involved in the modulation of gene expression. High-throughput RNA sequencing revealed hundreds of putative noncoding RNAs including the RgtA sRNA. Abundance of RgtA is strongly decreased in the absence of the Hfq protein and its expression is modulated by the activities of the two-component regulatory system BvgAS and another response regulator RisA. Whereas RgtA levels were elevated under modulatory conditions or in the absence of bvg genes, deletion of the risA gene completely abolished RgtA expression. Profiling of the $\Delta \operatorname{rgt} A$ mutant in the $\Delta b v g A$ genetic background identified the BP3831 gene encoding a periplasmic amino acid-binding protein of an $A B C$ transporter as a possible target gene. The results of site-directed mutagenesis and in silico analysis indicate that RgtA base-pairs with the region upstream of the start codon of the BP3831 mRNA and thereby weakens the BP3831 protein production. Furthermore, our data suggest that the function of the BP3831 protein is related to transport of glutamate, an important metabolite in the $B$. pertussis physiology. We propose that the BvgAS/RisA interplay regulates the expression of RgtA which upon infection, when glutamate might be scarce, attenuates translation of the glutamate transporter and thereby assists in adaptation of the pathogen to other sources of energy.
\end{abstract}

Keywords: sRNA; signal transduction; Bordetella; translational repression; riboregulation

\section{INTRODUCTION}

In the last two decades, small noncoding regulatory RNAs (sRNAs) have become recognized as very important modulators of gene expression in bacteria (Gottesman et al. 2006; Wagner and Romby 2015). Importantly, sRNAs are predominantly expressed under various stress conditions and help bacteria to adapt to changing environmental conditions (Hoe et al. 2013; Holmqvist and Wagner 2017). The most studied and best-characterized class of sRNAs acts at the post-transcriptional level by base-pairing with the target mRNAs and thereby modulating their

Corresponding author: vecerek@biomed.cas.cz

Article is online at http://www.rnajournal.org/cgi/doi/10.1261/rna. 067306.118 . stability and translational efficiency (Storz et al. 2004; Desnoyers et al. 2013). These activities may have either a positive or negative effect on target mRNA translation. Based on their chromosomal location, sRNAs are divided into two classes: cis- and trans-encoded. The cis-encoded sRNAs are transcribed antisense to their targets and therefore share perfect complementarity with the regulated mRNAs. On the other side, trans-encoded sRNAs are encoded at different genomic loci as their target genes and share only limited complementarity with target transcripts.

C 2018 Keidel et al. This article is distributed exclusively by the RNA Society for the first 12 months after the full-issue publication date (see http://rnajournal.cshlp.org/site/misc/terms.xhtml). After 12 months, it is available under a Creative Commons License (Attribution-NonCommercial 4.0 International), as described at http:// creativecommons.org/licenses/by-nc/4.0/. 
Of note, the majority of RNA transactions promoted by trans-encoded sRNAs result in repression of the protein synthesis as the base-pairing between sRNA and target mRNA leads to inhibition of translation and subsequent RNA degradation (Wagner 2009). In Gram-negative bacteria, the regulation based on imperfect sRNA/mRNA duplexes often requires activity of the RNA chaperones such as $\mathrm{Hfq}$ or the recently identified ProO protein (Smirnov et al. 2017). The Hfq protein forms a ring-shaped hexamer (Moller et al. 2002), which possesses several RNA-binding sites allowing simultaneous interaction with both sRNA and mRNA and stabilization of their interaction (Vogel and Luisi 2011; Updegrove et al. 2016). Besides its role in the stabilization of the RNA duplexes, Hfq can also actively remodel the structure of RNAs and increase or decrease the stability of interacting RNAs (Brennan and Link 2007; Vogel and Luisi 2011). Importantly, Hfqassociated sRNAs were proven to be involved in a wide variety of cellular processes, e.g., iron homeostasis, membrane remodeling, energy metabolism, and quorum sensing (Guillier et al. 2006; Papenfort and Vogel 2010; Bobrovskyy et al. 2015; Wagner and Romby 2015; Carrier et al. 2017). Given that a pathogenic lifestyle often requires a quick response to sudden changes in environmental conditions, it is not surprising that a large number of sRNAs produced by bacterial pathogens are involved in stress adaption and virulence (Wassarman 2002; Papenfort and Vogel 2010). Accordingly, Hfq seems to be important for the physiological fitness and virulence in several bacterial pathogens, including Bordetella pertussis (Sonnleitner et al. 2003; Ding et al. 2004; Sittka et al. 2007; Geng et al. 2009; Bibova et al. 2013).

Bordetella pertussis is a Gram-negative strictly human pathogen of the respiratory tract and the etiological agent of whooping cough (pertussis) (Mattoo and Cherry 2005). Despite vaccination programs, pertussis remains one of the 10 most common causes of vaccine preventable deaths (WHO 2006). Furthermore, pertussis incidence is currently on the rise in industrialized countries with highly vaccinated populations (Raguckas et al. 2007; Cherry 2010). While there are several reasons for this phenomenon, two major factors are contributing to the recent increase in pertussis cases: short-lived immunity induced by current acellular vaccines and pathogen adaptation leading to escape from immunity by antigenic variation (Mooi et al. 2014; Burdin et al. 2017). The reemergence of pertussis strongly suggests that a better understanding of the molecular mechanisms underlying the pathogenesis of $B$. pertussis is necessary to tackle the disease.

In order to colonize and damage the epithelial cells of the respiratory tract, $B$. pertussis expresses a complex set of virulence factors, including adhesins and toxins (Locht 1999). The expression of most of the virulence factors is controlled by the BvgAS two-component system, consisting of sensor kinase BvgS and response regulator BvgA, which, upon phosphorylation by BvgS, facilitates expression of the virulence-activated genes, vags (Cotter and Jones 2003). In principle, based on the BvgA phosphorylation status, three different phenotypes can be distinguished: $\mathrm{Bvg}^{+}$(virulent), $\mathrm{Bvg}^{-}$(avirulent), and $\mathrm{Bvg}^{\mathrm{i}}$ (intermediate). While the environmental signals sensed by BvgS kinase are not known, the BvgAS system can be rendered inactive by a process called phenotypic or antigenic modulation when $B$. pertussis cells are grown in the presence of magnesium sulfate or nicotinic acid (Lacey 1960; Melton and Weiss 1989). In contrast to the closely related $B$. bronchiseptica, the BvgAS system remains active at temperatures below $25^{\circ} \mathrm{C}$ in $B$. pertussis (Seydlova et al. 2017). The majority of factors expressed in the avirulent $\mathrm{Bvg}^{-}$state (virulence repressed genes, vrgs) is regulated by two factors, BvgR and another response regulator called RisA. While the Bvg-activated bvgR gene, lying downstream from the bvgS gene, is required for repression of $v$ rg genes in the $\mathrm{Bvg}^{+}$phase (Merkel and Stibitz 1995; Merkel et al. 1998), the RisA regulator is essential for expression of the vrg genes in the Bvg ${ }^{-}$mode (Jungnitz et al. 1998; Croinin et al. 2005; Stenson et al. 2005; Coutte et al. 2016). The exact mechanism of the BvgR-RisA interplay was not completely understood; however, recently it was suggested that BvgR is not a typical repressor interacting with promoters of repressed genes but represents a di-guanylate phosphodiesterase degrading the second messenger c-di-GMP to GMP (Chen et al. 2017). It is presumed that in the $\mathrm{Bvg}^{-}$mode, when BvgR is not produced, the c-di-GMP accumulates and binds to response regulator RisA phosphorylated by its cognate kinase RisK. Phosphorylated RisA in complex with c-di-GMP binds to vrg promoters and increases their activity (Coutte et al. 2016; Chen et al. 2017).

We have shown that the Hfq protein significantly affects the expression of more than $10 \%$ of the $B$. pertussis genes (Bibova et al. 2015) and that the Hfq protein is required for B. pertussis virulence (Bibova et al. 2013). These observations suggested that sRNAs could play an important role in the physiological fitness of this pathogen. So far, several sRNAs have been identified in B. pertussis (Hot et al. 2011); however, their function and possible targets remained unknown. The extensive impact of the hfq gene deletion on transcriptomic profiles in $B$. pertussis motivated us to search for regulatory RNAs on a genome-wide scale. A recently determined primary transcriptome of $B$. pertussis (Amman et al. 2018) revealed a large variety of noncoding RNAs, including sRNAs. In this study, we characterize one of the identified sRNAs, which, based on its possible function, was designated RgtA (repressor of glutamate transport). We determined its chromosomal location, transcriptional start site, and size. We show that RgtA synthesis is substantially induced under modulating conditions and that its expression requires the activity of RisA transcriptional regulator. Furthermore, we present a possible target 
A

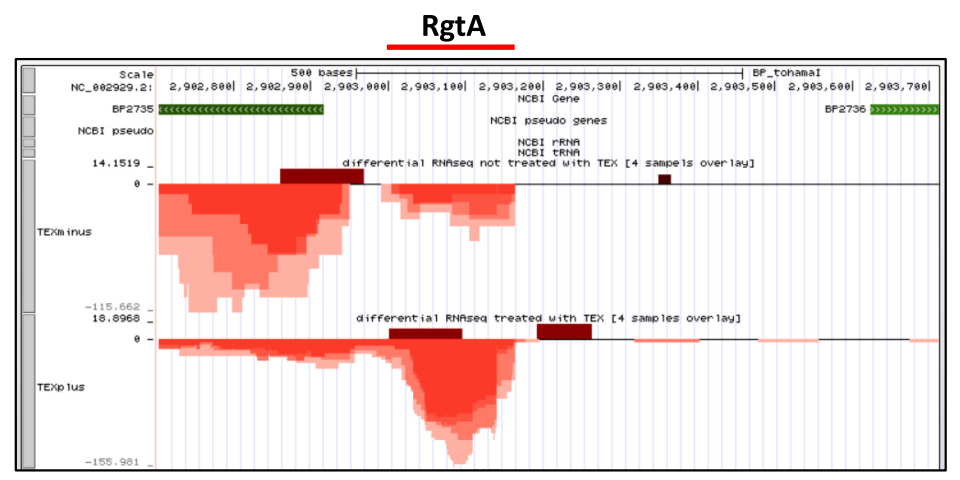

B

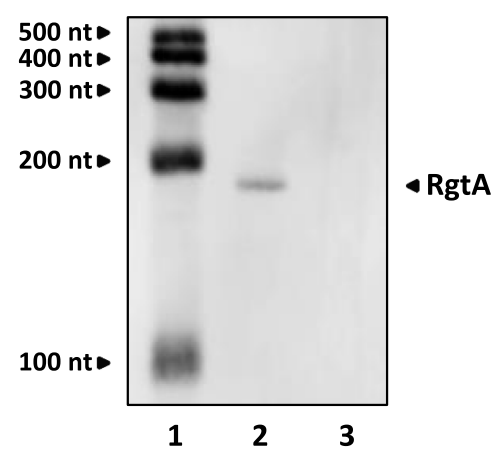

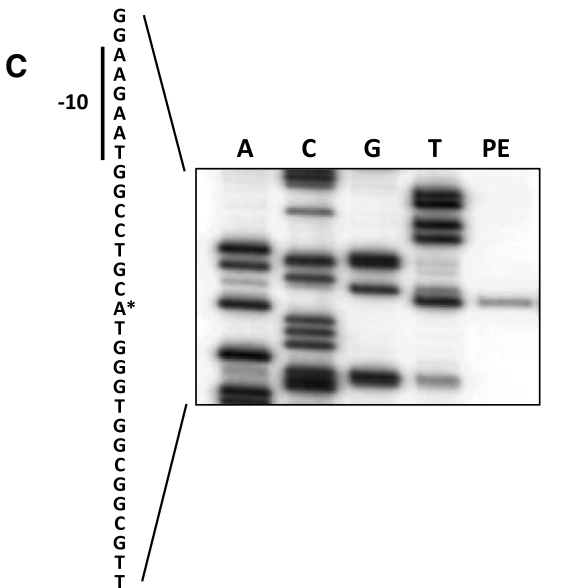

D

-283 AGCCGCTTAATGTTGAAACTAATTGTGTITTICGGGCTGCTTTGTAGCCAATTGCGTGGAAATGGAGATTGCTGCAAGGCGGGCTGGGGTGTTTCGC RisA_1 Risa_2

RisA_3

-183 GCTGCCCATGGCGCGCCGATGTCGATCGCGGACCCAATGCCCATGCGGCTTTCCGTCATGCCGGCAAGCCGGCCGGGGCGCCTGCCGCGCGCATTTGCTT $\longrightarrow+1$ -83 GTCATAAATGTATCCACGCCTIGATACGCGGGTTIACACGTAAGCGCTIGGCGCGGCCGTGCCCCTCGGGAAGAATGGCCTGCATGGGTGGCGGCGTTGC +18 CGCTGTCCATGCAGGCCTGGAACGGTGTCGCGACAATCGACCCGTTCCGTTGGGCCACGGGGCGTAGCTGACGGCTGCTTCTCGGGATCGCCGGCTGGCG

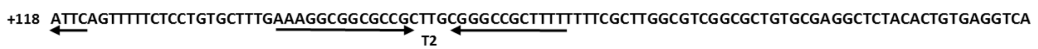

FIGURE 1. Identification and characterization of RgtA sRNA in B. pertussis. (A) Visualization of the dRNA-seg normalized data set $( \pm$ treatment with terminal exonuclease) showing the region between the BP2735 and BP2736 genes. Graphs display sequencing depth of the positive (dark red) and negative (light red) strands. (The different color intensities depict the different library replicates.) Gene annotations are depicted as green arrows. Red bar above the picture denotes the genomic position of RgtA RNA. (B) Detection of RgtA by northern blot analysis. Total RNA isolated from B. pertussis Tohama I (lane 2) and $\Delta$ rgtA (lane 3) strains was separated on 8\% PAA-8M urea gel, transferred to membrane, and probed with biotinylated oligo specific to RgtA. Biotinylated Century-Plus RNA ladder was loaded as a molecular size marker (lane 1). (C) Determination of the transcriptional start site of RgtA by primer extension analysis. The product of the primer extension reaction (PE, lane 5) was separated together with sequencing reactions performed with the primer used for primer extension (lanes 1-4) on a 6\% polyacrylamide-8 $\mathrm{M}$ urea gel. Only the relevant part of the autoradiograph is presented. The sequence of the coding strand is shown on the left with the transcriptional start site (asterisk) and the plausible -10 sequence (vertical line). (D) Nucleotide sequence map of the rgtA locus. The transcriptional start site identified by primer extension and dRNA-seq analysis (rectangular arrow, +1 ), plausible -35 and -10 promoter sequences (underlined), putative RisA binding sites (gray boxes), and two possible terminators (convergent arrows) are depicted.

of RgtA RNA, the mRNA encoding the periplasmic amino acid-binding protein BP3831.

\section{RESULTS}

\section{Identification and characterization of the RgtA sRNA}

Recently, we applied high-throughput sequencing approaches (RNA-seq and differential RNA-seq) to decipher the transcriptional landscape of $B$. pertussis (Amman et al. 2018). One of the sRNAs discovered by dRNA-seq analysis was identified as an unknown transcript located within the intergenic region between BP2736 and BP2735 genes and originating from the negative strand (Fig. 1A). To validate the RNA-seq data, we assayed the synthesis of RgtA in the wt and $\Delta r g t A$ strains by northern blot analysis using a probe specific to the rgtA locus. The result of the northern blot analysis was in agreement with our transcriptomic data since we detected an approximately $180 \mathrm{nt}$ long transcript that seemed to be specific as the RNA isolated from $\Delta r g t A$ mutant did not hybridize with the probe (Fig. 1B). Next, we determined the transcriptional start site of the RgtA RNA by primer extension analysis as an A residue at position 2,903,162 within the B. pertussis genome (Parkhill et al. 2003), again fully in agreement with the results of the dRNA-seq analysis (Fig. 1C). Upstream of the transcriptional start site we identified plausible -35 (TTGGCG) and -10 (AAGAAT) promoter sequences optimally spaced by $17 \mathrm{bp}$ (Fig. 1D). Two possible terminator structures were predicted at the $3^{\prime}$ end of $\operatorname{rgt} A$, and using 
northern blot analysis we determined that both structures are present in the RgtA transcript (data not shown). This observation allowed us to conclude that the size of RgtA is $174 \mathrm{nt}$. Nucleotide sequence alignment revealed that the rgtA locus is well-conserved ( $98 \%$ identity) in closely related species B. bronchiseptica and B. parapertussis (Supplemental Fig. S1A). In support, northern blot analysis proved that both related species produce RgtA homologs (Supplemental Fig. S1B).

\section{Expression of RgtA is repressed by the BvgAS two-component system}

Most of the regulatory small RNAs are induced in response to stress stimuli and often require $\mathrm{Hfq}$ for their stability and function. Interestingly, northern blot analysis revealed that when compared to wt strain, the abundance of RgtA is strongly reduced in the $\Delta h f q$ strain, indicating that $\mathrm{Hfq}$ protein may contribute to stability of this sRNA (Fig. 2A). Next, we used several stress conditions, including cold and heat shock, oxidative, and membrane stresses, but we did not observe any significant changes in RgtA expression under tested conditions (data not shown). Interestingly, cells grown under modulatory conditions known to induce avirulent $\mathrm{Bvg}^{-}$phenotype $(50 \mathrm{mM}$ magnesium sulfate or $20 \mathrm{mM}$ nicotinic acid) produced increased amounts of RgtA sRNA (Fig. 2B). These results suggested that rgtA belongs to virulence repressed genes and its expression is up-regulated in the absence of a functional bvg system. Of note, growth at low temperature did not affect RgtA production (Fig. 2B), which is in line with our recent observation that in contrast to $B$. bronchiseptica, the bvg system of $B$. pertussis is active at temperatures below $25^{\circ} \mathrm{C}$ (Seydlova et al. 2017). To corroborate our observations, we decided to genetically inactivate the bvg system by construction of $\triangle b v g A, \Delta b v g S$, and $\Delta b v g R$ strains and to determine the RgtA synthesis in these mutants by northern blot analysis. As shown in Figure 2C, the expression of RgtA was increased in all the bvg deletion mutants.

B three experiments.
Collectively, these results clearly showed that under chemically or genetically induced $\mathrm{Bvg}^{-}$conditions, the abundance of the RgtA is substantially increased.

\section{RisA regulator activates the expression of RgtA}

It has been demonstrated that under $\mathrm{Bvg}^{-}$conditions the response regulator Ris $A$ is required for efficient expression of $v$ rg genes. Thus, repression of RgtA synthesis by the bvg system suggested that expression of the rgtA gene could be RisA-dependent. To test this assumption, the RgtA
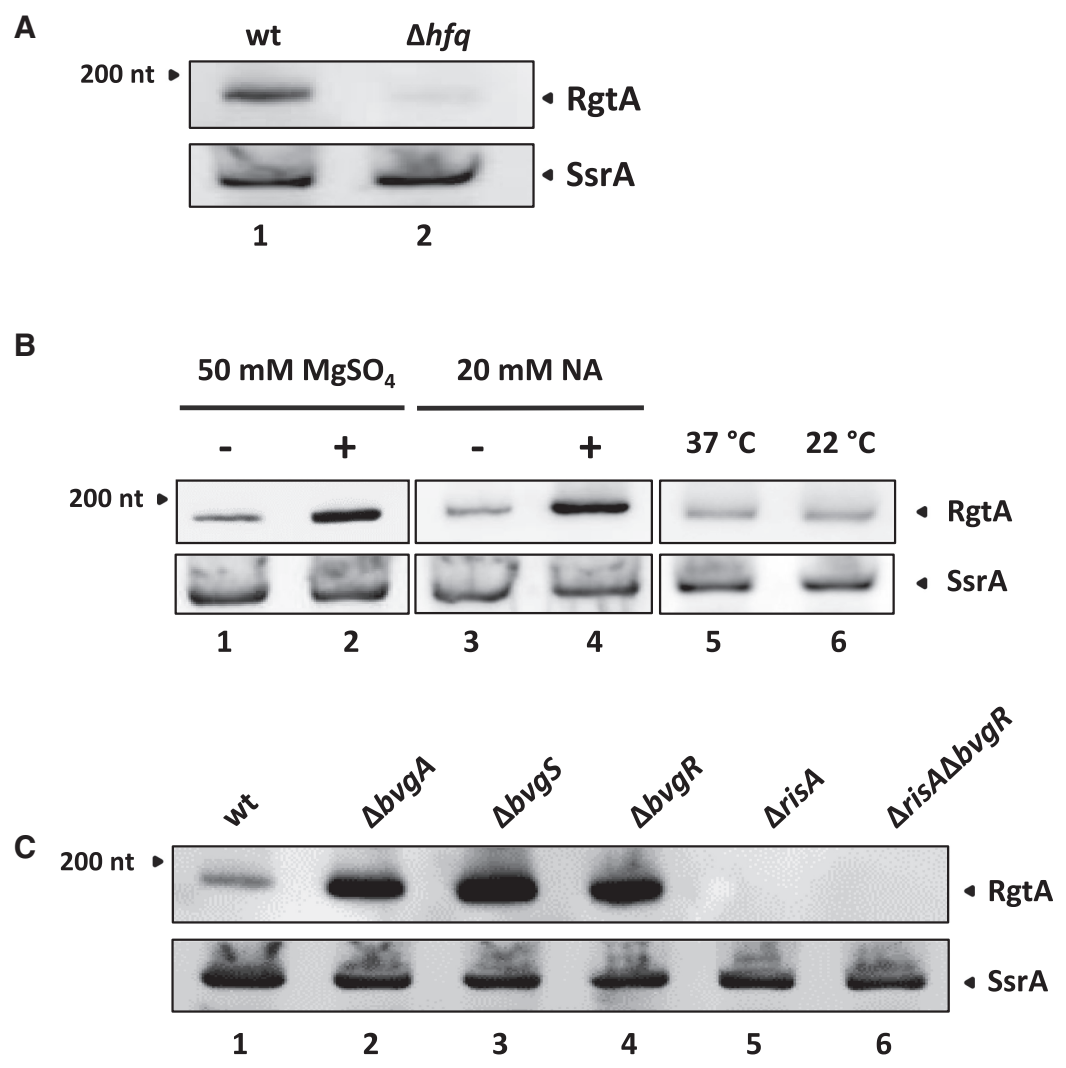

FIGURE 2. Abundance of RgtA is affected by the Hfq protein and phenotypic modulation. (A) Northern blot analysis was performed using total RNA isolated from Tohama I strain (lane 1) and its isogenic $\Delta h f q$ mutant (lane 2) probed with biotinylated probes specific to RgtA (upper panel) and to SsrA RNAs (lower panel, loading control). Only relevant parts of the membranes are shown. The result is a representative of three independent experiments. (B) B. pertussis Tohama I strain was grown in SS medium in the absence or presence of magnesium sulfate (lanes 1,2) and nicotinic acid (lanes 3,4) for $2 \mathrm{~h}$. In another experiment, Tohama I cells were grown in parallel at $37^{\circ} \mathrm{C}$ and $22^{\circ} \mathrm{C}$ for $48 \mathrm{~h}$ in SS medium (lanes 5,6). At these time points cells were harvested and isolated RNA was probed with biotinylated RgtA-specific probe and subjected to northern blot analysis (upper panels). Signals obtained upon rehybridization of the membrane with SsrA-specific probe (lower panels) served as loading control. Only relevant parts of the membranes are shown. The result is a representative of four experiments. (C) B. pertussis Tohama I strain (lane 1) and its isogenic mutants carrying deletions of bvgA (lane 2), bvgS (lane 3), bvgR (lane 4), $\Delta$ risA (lane 5), and $\Delta$ risA $\Delta b v g R$ (lane 6) genes were grown in SS medium to exponential phase. RNA isolated from harvested cells was probed with biotinylated RgtA-specific probe and subjected to northern blot analysis. Signals obtained upon rehybridization of the membrane with SsrA-specific probe (lower panels) served as loading control. Only relevant parts of the membranes are shown. The result is a representative of 
transcript levels in the $\Delta$ risA strain were analyzed by northern blot method. When compared to wt strain and especially to all bvg mutants, the RgtA synthesis was completely abolished in the $\Delta$ risA background (Fig. 2C). The absolute requirement of RisA factor for RgtA production became even more evident when we determined the RgtA levels in the $\Delta b v g R$ genetic background. As shown in Figure 2C, when compared to $\Delta b v g R$ mutant (increased abundance of RgtA due to lack of BvgR), the RgtA levels in the $\Delta$ risA $\Delta b v g R$ double mutant were also completely ablated. Apparently, the absence of a functional bvg system is not sufficient for RgtA expression when the RisA activator is lacking. To further characterize the RisA requirement for RgtA expression we searched for possible RisA-binding motifs in the promoter region of the rgtA gene. The consensus sequence of the RisA-binding site has been determined as the 7-bp motif 5'-AAAT(G/T)TA-3' (Croinin et al. 2005). We identified several nearly perfect matches to this RisAbinding motif in the promoter region of the rgtA gene. In fact, the 60-bp region spanning $n t-277$ to -217 relative to the transcriptional start site contains three RisA-binding motifs in close proximity (Figs. 1D, 3A). Thus, we created a deletion mutant termed $\operatorname{rgt} A \Delta 277 / 217$ lacking this 60bp region and analyzed its ability to produce RgtA sRNA.

A
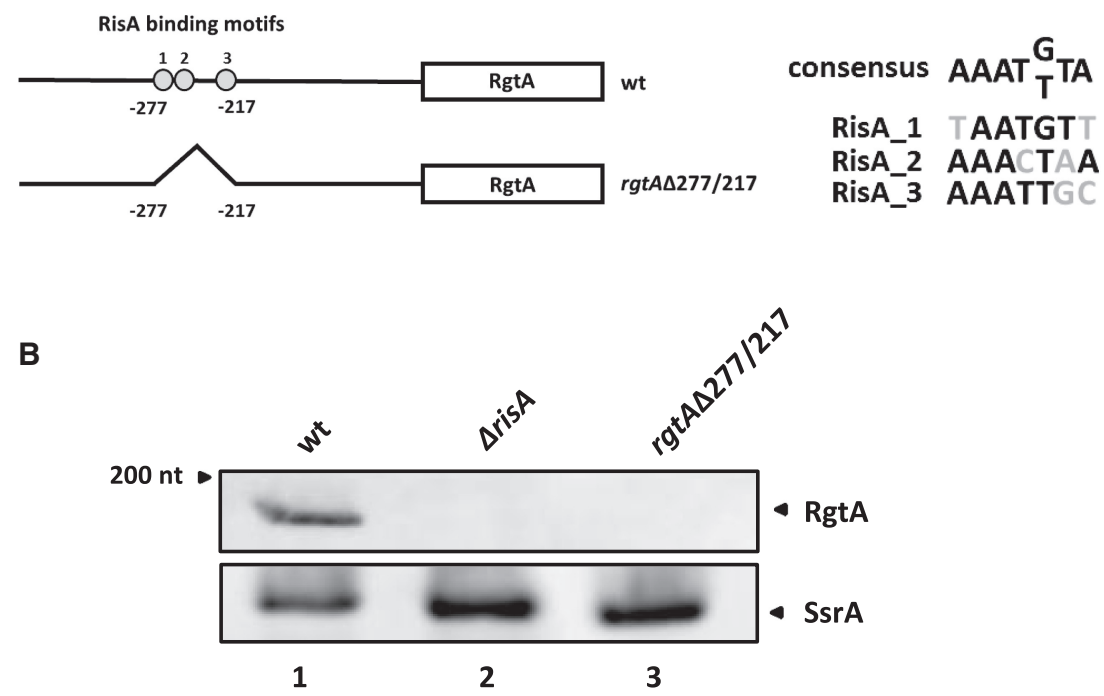

FIGURE 3. The requirement of the response regulator RisA for rgtA expression. (A) Schematic representation of RisA binding motifs in rgtA promoter region. (Left) Three plausible RisA binding sites (gray circles 1-3) are present in a 60-bp region (-277 to -217 ) upstream of the rgtA transcriptional start site. This 60-bp region has been deleted, resulting in the rgtA $\Delta 277 / 217$ mutant. (Right) Sequences of canonical RisA-binding motif as well of three RisA-binding motifs found upstream of the rgtA promoter are depicted; nucleotides different from consensus are in gray. (B) B. pertussis Tohama I strain (lane 1) and its isogenic $\Delta$ risA (lane 2) and rgtA $\Delta 277 / 217$ (lane 3) mutants were grown in SS medium to exponential phase. RNA isolated from harvested cells was probed with biotinylated RgtA-specific probe and subjected to northern blot analysis (upper panel). Signals obtained upon rehybridization of the membrane with SsrA-specific probe (lower panel) served as loading control. Only relevant parts of the membranes are shown. The result is a representative of two experiments.
Indeed, the synthesis of the RgtA in this mutant was totally abolished as already observed in the $\Delta$ risA strain, thereby indicating that this 60-bp region is required for RisA-depen-

\section{BP3831 is a possible target of RgtA-mediated regulation}

Our results proved that expression of RgtA is controlled by two different signal transduction systems and thereby indicated that this sRNA may play a significant role in the physiology of $B$. pertussis. Therefore, we decided to characterize its possible function and identify its target genes. First, we constructed the $\Delta$ rgtA mutant of $B$. pertussis in the $\triangle b v g A$ background with the rationale that expression of the rgtA gene is increased in the Bvg mode and under these conditions we may better identify biologically relevant targets. Therefore, we compared script profiles of the double $\Delta b v g A \Delta r g t A$ mutant RgtA synthesis) with that of $\Delta b v g A$ strain (increased hesis of RgtA) by DNA microarray technique. Among ulation (Supplemental Table S1), the most prominent change in expression was found for the BP3831 gene (+1.2 $\log _{2}$ fold change). BP3831 is annotated as a periplasmic amino acidbinding protein of a putative $A B C$ transporter within the $B$. pertussis genome (Parkhill et al. 2003). Microarray data suggested that presence of RgtA would display a negative effect on BP3831 transcript levels and consequently, on BP3831 protein levels. To verify this hypothesis, the levels of BP3831 protein were examined by immunoblotting. Western blot analysis with protein samples isolated from cells of the wild-type, $\Delta$ rgtA, $\Delta$ bvgA, and $\Delta$ bvgA $\Delta$ rgtA strains revealed that when compared to $\Delta$ bvgA strain (increased expression of RgtA RNA), the amounts of BP3831 protein in $\Delta$ bvgA $\Delta$ RgtA (lack of RgtA expression) were significantly increased (Fig. 4A). There was no significant difference between the wildtype and $\Delta$ rgtA strain most probably due to overall lower production of RgtA in the wt strain (see Fig. 2C). This result was in agreement with our microarray data and confirmed the negative effect of the RgtA RNA on the BP3831 protein production. In many cases, the trans-encoded sRNAs exhibit their negative effects 
A

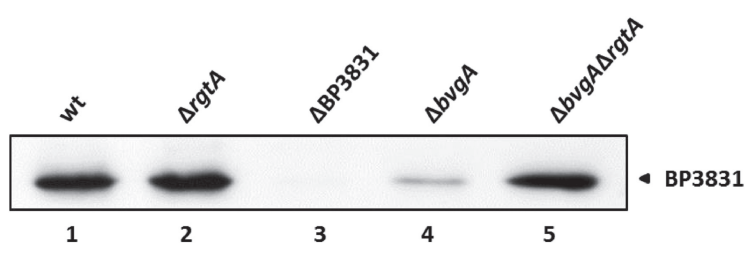

B

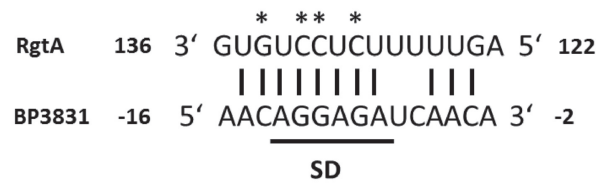

C

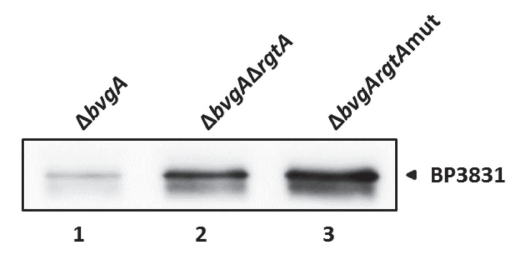

FIGURE 4. Inhibitory effect of the RgtA sRNA on BP3831 protein production. (A) B. pertussis Tohama I (lane 1) and its isogenic $\Delta$ rgtA (lane 2) $\triangle B P 3831$ (lane 3), $\Delta$ bvgA (lane 4), and $\Delta$ bvgA $\Delta$ rgtA (lane 5) mutants were grown in SS medium to exponential phase. Samples of cell lysates equivalent to $0.1 \mathrm{OD}_{600}$ unit were separated on $12.5 \%$ SDSPAGE gels and analyzed by immunoblotting using anti-BP3831 antibodies. Only relevant parts of the membranes are shown. The result is a representative of three experiments. (B) Schematic representation of the putative base-pairing between the RgtA RNA and BP3831 mRNA. Nucleotides 122 to 136 of RgtA are complementary to -2 to -16 region of BP3831 mRNA containing the Shine and Dalgarno sequence (SD). Nucleotides marked with an asterisk were mutated to disrupt the possible base-pairing between the RgtA and BP3831 transcripts in the $\triangle$ bvgArgtAmut strain. (C) The effect of the mutations introduced into RgtA RNA on BP3831 protein levels. B. pertussis Tohama I $\Delta$ bvgA (lane 1), $\Delta$ bvgA $\Delta r g t A$ (lane 2), and $\Delta$ bvgArgtAmut (lane 3) mutants were grown in SS medium to exponential phase. Samples of cell lysates equivalent to $0.1 \mathrm{OD}_{600}$ unit were separated on $12.5 \%$ SDS-PAGE gels and analyzed by immunoblotting using anti-BP3831 antibodies. Only relevant parts of the membranes are shown. The result is representative of two experiments.

on translation by blocking the ribosome loading. We searched in silico for possible interactions between the RgtA sRNA and the BP3831 mRNA. Using the program CopraRNA (http://rna.informatik.uni-freiburg.de/ CopraRNA/Input.jsp) (Wright et al. 2014), we identified a 13-nt region within the RgtA sequence that shared partial complementarity to the region immediately upstream of the BP3831 start codon and that also included the Shine and Dalgarno sequence (Fig. 4B). As depicted in Supplemental Figure S2, this 13-nt region within the RgtA is predicted by mfold RNA folding server (Zuker 2003) to be single-stranded. To prove this predicted RNA-RNA interaction, we introduced four chromosomally located point mutations within this 13-bp region into the $\triangle$ bvgA strain yielding the $\triangle$ bvgArgtAmut strain. As shown in Figure $4 C$, when compared to the $\triangle b v g A$ strain, the $\Delta$ bvgArgtAmut strain produced increased amounts of BP3831 protein that were similar to those found in the $\Delta$ bvgA $\Delta$ rgtA (lacking the rgtA expression completely). Collectively, these results indicated that RgtA may interfere with the BP3831 production most likely by blocking the ribosome binding.

\section{BP3831 is presumably involved in glutamate uptake}

BP3831 is tentatively annotated as a putative periplasmic amino acid-binding protein of an $A B C$ transporter in the $B$. pertussis genome. BLAST search unveiled that the BP3831 protein exhibits high homology with the entry $4 Z 9 N$ in the PDB protein database (10.2210/pdb4Z9N/ $p d b)$. This entry contains $X$-ray diffraction data of an $A B C$ transporter periplasmic binding protein from Brucella ovis that had been cocrystallized with glutathione. Interestingly, the binding pocket of the $B$. ovis protein shares nine of 11 amino acids with the BP3831 transporter (data not shown). Glutathione (GSH) is a tripeptide consisting of three amino acids, glutamate, cysteine, and glycine, and in the SS medium serves as an important antioxidant due to its reducing capacity. Nevertheless, glutathione was recently demonstrated as a suitable source of sulfur for $B$. pertussis and as such can replace cysteine (Branco Dos Santos et al. 2017). Therefore, to decipher if BP3831 is responsible for GSH binding, we cultivated both wt and $\triangle B P 3831$ cells in the medium with or without cysteine with the rationale that if the GSH would be the specific substrate for BP3831, the mutant strain should not grow in medium lacking cysteine (the source of sulfur would be missing). Interestingly, when compared to wt strain, the mutant strain manifested observable growth deficit; however, it grew equally well in the media with or without the cysteine thereby ruling out the GSH as a substrate (Fig. 5A). Therefore, we focused on the other two amino acids that are included in the SS medium, glutamate and proline. First, the observed growth defect of the $\triangle B P 3831$ strain was reproducible regardless if proline was present or absent in the medium and therefore, we excluded also proline as the substrate of BP3831 transporter (Fig. 5B). However, when we compared growth of the wild-type and $\triangle B P 3831$ strains in the medium lacking glutamate (proline was the sole source of the carbon and nitrogen), we did not observe any significant difference (Fig. 5C), suggesting that in the absence of glutamate the BP3831 transporter does not confer any selective advantage. Hence, we concluded that the BP3831 transporter most likely exhibits the affinity for glutamate. Based on the observed negative effect of RgtA sRNA on BP3831 production (Fig. 4), we inspected the possible role of RgtA in the regulation of the glutamate uptake. Therefore, we analyzed the growth properties of the $\triangle b v g A$ (high levels of RgtA) and $\Delta$ bvgA $\Delta$ rgtA (no RgtA expression) strains in 
A

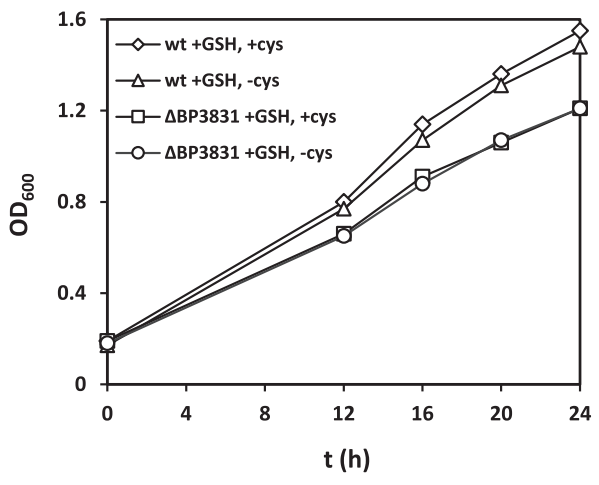

C

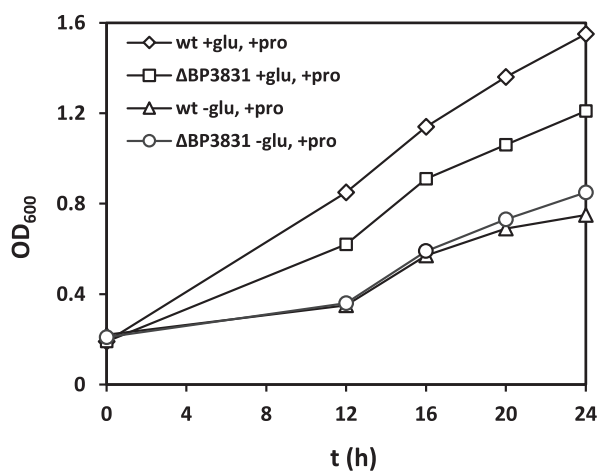

B

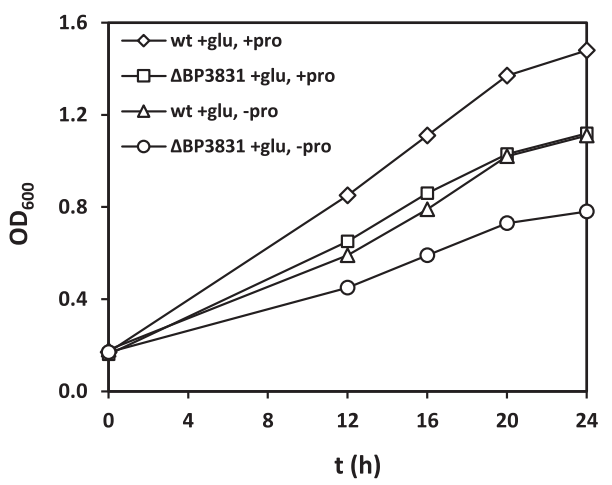

D

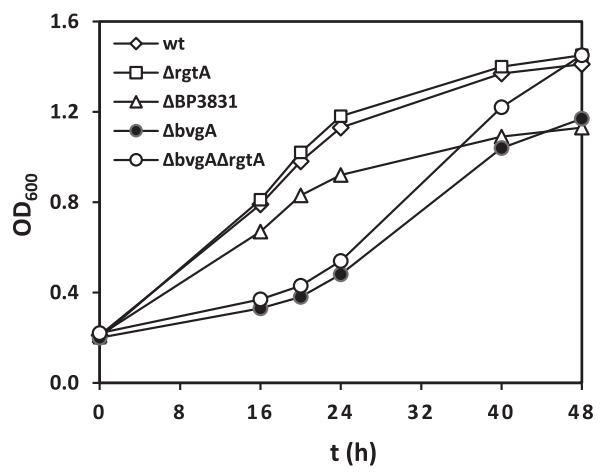

FIGURE 5. Requirement of the BP3831 transporter for growth of B. pertussis in chemically defined media. (A) B. pertussis Tohama I strain and its isogenic $\triangle B P 3831$ mutant were grown in chemically defined SS medium in the presence (diamonds and squares, respectively) or absence (triangles and circles, respectively) of cysteine. (B) B. pertussis Tohama I strain and its isogenic $\triangle B P 3831$ mutant were grown in chemically defined SS medium in the presence (diamonds and squares, respectively) or absence (triangles and circles, respectively) of proline. (C) B. pertussis Tohama I strain and its isogenic $\triangle B P 3831$ mutant were grown in chemically defined SS medium in the presence (diamonds and squares, respectively) or absence (triangles and circles, respectively) of glutamate. (D) B. pertussis Tohama I strain (diamonds) and its isogenic $\Delta$ rgtA (squares), $\triangle B P 3831$ (triangles), $\triangle$ bvgA mutant (filled circles), and $\Delta$ bvgA $\Delta r g t A$ (empty circles) mutants were grown in chemically defined SS medium with the glutamate as the sole source of carbon and nitrogen (no proline). The results in all panels are representative of three experiments.

the medium with glutamate as the sole source of energy (no proline). As shown in Figure 5D, wild-type (producing low amounts of RgtA) and $\Delta$ rgtA strains grew very similarly whereas as expected, the $\triangle B P 3831$ strain showed impaired growth (see Fig. 5A). In agreement with our assumptions, the double $\Delta$ bvgA $\Delta$ rgtA mutant lacking RgtA RNA displayed better growth properties and reached higher OD values (equal to wild-type strain) when compared to $\Delta b v g A$ strain.

\section{DISCUSSION}

In this work we present the first fully characterized regulatory sRNA RgtA in the human pathogen B. pertussis. Furthermore, we identified its putative target gene as well as the possible RgtA-dependent regulatory mechanism and we propose that this sRNA is involved in control of transport of glutamate, an important source of carbon and nitrogen.

Importantly, RgtA displays several characteristics typical for a trans-encoded sRNA as it is (i) encoded within the intergenic region between genes BP2735 and BP2736, (ii) its size is $174 \mathrm{nt}$, and (iii) its abundance is Hfq-dependent. Primer extension and northern blot analyses revealed that RgtA is transcribed from the negative strand and that the $5^{\prime}$ end of RgtA starts at nt 2,903,162 in the $B$. pertussis Tohama I genome (accession number: NC 002929.2). Importantly, the sequence of the rgtA gene including promoter region and putative RisA-binding sites is highly conserved in the closely related species $B$. bronchiseptica RB50 and B. parapertussis 12822 (Supplemental Fig. S1A). Likewise, the region upstream of the initiation codon including the Shine and Dalgarno sequence is well preserved in the BP3831 gene and its homologs (data not shown). These observations indicate that the suggested sRNA-mRNA interaction might be functional also in related Bordetella species. Northern blot analysis confirmed that both related species produce RgtA RNA, although the $B$. parapertussis RgtA homolog seems to be smaller in size.

While we could not observe any significant changes in RgtA expression under several stress conditions, we 
discovered that under modulatory conditions, inducing avirulent $\mathrm{Bvg}^{-}$phase, the abundance of this sRNA is substantially increased. This finding was corroborated using mutants created in the bvgASR locus and identified RgtA as a virulence repressed gene. The expression of most of the vrgs was shown to be dependent on another response regulator, RisA, which in its phosphorylated form binds c-di-GMP as a cofactor and activates expression of vrg genes (Coutte et al. 2016; Chen et al. 2017). Therefore, our data on rgtA expression nicely fit in the proposed model integrating the roles of BvgAS, BvgR, and RisA regulatory systems. RisA requirement was indirectly confirmed by deletion of three putative RisA-binding sites within a 60-bp region between positions -277 and -217 relative to the start site of the rgtA transcript, which completely abolished transcription. Interestingly, deletions between positions -271 and -159 relative to the transcription start site completely disrupted RisA-dependent regulation of the vrg6 gene expression (Croinin et al. 2005). These observations suggest that regions located $\sim 270$ bp upstream of the start of transcription may be essential for RisA-dependent activation of the vrg genes. Nevertheless, additional experiments would be necessary to define the specific sequences contributing to binding of RisA and to demonstrate direct RisA interaction with the rgtA promoter.

Currently available next-generation sequencing technologies as well as improved bioinformatics tools led to the discovery of myriads of sRNAs in numerous bacteria. Nevertheless, characterization of their regulatory roles and identification of their interaction partners is strenuous and time consuming. Importantly, in our study we identified a possible target of the RgtA-mediated regulation, the periplasmic amino acid-binding protein of an $A B C$ transporter BP3831. Transcriptomic profiling of the wt and $\Delta r g t A$ strains did not reveal any significantly modulated genes (data not shown) most probably due to lower production of RgtA under $\mathrm{Bvg}^{+}$conditions. Nevertheless, when the $\mathrm{Bvg}^{-}$conditions were introduced by deletion of the bvgA gene, comparative analysis of the $\Delta$ bvgA $\Delta r g t A$ and $\triangle b v g A$ strains unveiled BP3831 as the most deregulated gene. Down-regulation of the BP3831 production in the presence of RgtA in vivo, as well as in silico prediction of the possible RgtA sRNABP3831 mRNA interaction, suggested a negative effect of RgtA on BP3831 protein levels. We verified this assumption by site-directed mutagenesis of several bases in RgtA involved in the predicted base-pairing with the BP3831 mRNA. Notably, the levels of the BP3831 protein in this mutant were similar to those observed in the $\Delta r g t A$ mutant, suggesting that in line with the in silico modeling, the RgtA RNA may overlap with the Shine and Dalgarno sequence of the BP3831 transcript and impair the ribosome loading.

Finding the target of the RgtA-dependent regulation encouraged us to characterize the function of the
BP3831 transporter in the cellular metabolism and, consequently, to decipher the possible biological role of RgtA. The BP3831 protein has been only tentatively annotated as a periplasmic amino acid-binding protein. Interestingly, it has been shown that multiple periplasmic binding proteins of the $A B C$ transporters family are part of the Hfq-regulon in several organisms and a direct interaction between various sRNAs and $A B C$ transporter mRNAs has been proven as well (Antal et al. 2005; Sharma et al. 2007; Wilms et al. 2012). The growth analysis of strains lacking BP3831 or rgtA genes suggests that BP3831 is most likely involved in the uptake of glutamate, although we are aware of rather subtle effects caused by these deletions. Only partially impaired growth of the $\triangle B P 3831$ strain in the medium with glutamate as the sole source of energy indicates that BP3831 may have yet another substrate specificity or that there are still other glutamate transporters produced by $B$. pertussis cells. Indeed, several genes within the Tohama I genome are predicted to encode periplasmic binding proteins of unknown specificity, e.g., BP0558 and BP1529 proteins share $61 \%$ sequence identity and $81 \%$ sequence positivity with BP3831 transporter. Therefore, it is very well possible that some of these proteins can deliver the glutamate also in the absence of BP3831 and mask the effects conferred by RgtA-mediated repression or BP3831 deletion. Recently, increased abundance of the BP3831 protein in the secretome of the Australian epidemic strain was documented and suggested to be linked with increased fitness of this strain (Luu et al. 2018). Furthermore, BP3831 protein was identified within the surface proteome of $B$. pertussis and was also found to be immunogenic (Tefon et al. 2011; Williamson et al. 2015). B. pertussis as a strictly human pathogen faces upon infection several stresses resulting from nutrient scarcity as well as from the immune response of the host. In this respect, the RgtA-dependent reduction of BP3831 levels may help the pathogen to adapt to new sources of nutrients (other than glutamate) and/or decrease the antigenicity by reduction of the amounts of immunogenic protein. In support, the expression of BP3831 was significantly reduced in mousepassaged $B$. pertussis cells recovered $12 \mathrm{~d}$ post infection (Bibova et al. 2015). Furthermore, glutamate starvation was shown to result in reduced production of virulence factors (Nakamura et al. 2006) and may be then considered as a signal to reprogram the metabolism in order to persist within the host. Indeed, multiple metabolic pathways are up-regulated in the $\mathrm{Bvg}^{-}$phase and potentially help to overcome the environmental and nutritional stress (Moon et al. 2017). Interestingly, bvg ${ }^{-}$mutants have been shown to accumulate among persistent $B$. pertussis cells within the upper respiratory tract of experimentally infected rhesus monkeys (Karataev et al. 2016). In this respect, it is possible that RisAK of $B$. pertussis may play similar roles as the RisAS system of $B$. bronchiseptica, which controls 
expression of vrgs required for intracellular survival and persistence in the mouse model of infection (Jungnitz et al. 1998; Zimna et al. 2001). In conclusion, the RisA-dependent small regulatory RNA RgtA represents a regulatory factor that is functionally related to the $\mathrm{Bvg}^{-}$mode of the B. pertussis life cycle. We speculate that RgtA-mediated riboregulatory activity helps the pathogen to adapt to nutritional stress and reduce the host immune responses and, consequently, to establish persistent infection.

\section{MATERIALS AND METHODS}

\section{Bacterial strains and growth conditions}

The Bordetella pertussis Tohama I strain (Kasuga et al. 1954) and its isogenic deletion mutants as well as Bordetella bronchiseptica RB50 (Cotter and Miller 1994) and Bordetella parapertussis 12822 (Heininger et al. 2002) strains were grown on Bordet-Gengou agar (BGA) plates supplemented with 15\% sheep blood for 3 to $4 \mathrm{~d}$ at $37^{\circ} \mathrm{C}$. For liquid cultures, bacteria were grown in StainerScholte (SS) medium (Stainer and Scholte 1970) supplemented with $0.1 \%$ cyclodextrin and $0.5 \%$ casamino acids (Difco) at $37^{\circ} \mathrm{C}$. In experiments where the growth was monitored in chemically defined media, the casamino acids were omitted. For phenotypic modulation experiments with magnesium sulfate or nicotinic acid an overnight culture of $B$. pertussis was diluted to OD of 0.4. After reaching OD 0.5, the culture was divided into two flasks. To modulated cultures, either magnesium sulfate or nicotinic acid was added to $50 \mathrm{mM}$ and $20 \mathrm{mM}$ final concentrations, respectively. Cultures in second flasks without modulators served as controls. Samples for RNA isolation were taken $2 \mathrm{~h}$ after addition of modulators. For growth at $22^{\circ} \mathrm{C}$, the $B$. pertussis cultures were cultivated at $37^{\circ} \mathrm{C}$ for $14 \mathrm{~h}$ and then further passaged either at $37^{\circ} \mathrm{C}$ (control) or at $22^{\circ} \mathrm{C}$ to achieve at least three cell divisions ( $>48$ h). Escherichia coli strains were cultured on Luria-Bertani (LB) agar or in LB broth.

\section{Construction of deletion mutants}

The deletions or point mutations were introduced into $B$. pertussis Tohama I strain chromosome as already described (Bibova et al. 2013). In general, two DNA fragments of 750 bp corresponding either to the upstream or the downstream flanking regions of the corresponding gene were created using PCR. The upstream fragment (containing the start codon of the gene at the $3^{\prime}$-end) and the downstream fragment (containing the stop codon of the gene at the $5^{\prime}$-end) were cleaved at the $3^{\prime}$ end and the $5^{\prime}$-end, respectively, with the same restriction enzyme and then ligated. The ligation mixture was then used as a template to create $\sim 1.5 \mathrm{~kb}$ PCR product. This amplified PCR product was then ligated into the allelic exchange plasmid pSS4245. The resulting plasmid was transformed into the E. coli SM10 strain (donor strain) and transferred to B. pertussis Tohama I (recipient strain) by conjugation, as described elsewhere (Inatsuka et al. 2010). After two recombination events, the strain carrying the desired markerless in-frame deletion (where only the start and stop codons of the deleted gene separated by the restriction site were preserved) was obtained.
Successful chromosomal deletions, point mutations, and the sequences of the flanking regions were confirmed by DNA sequencing. Bordetella sp. strains used in this study are listed in Supplemental Table 2. Primers used for the construction of the mutants are listed in Supplemental Table 3.

\section{DNA microarrays}

B. pertussis $\Delta b v g A$ and $\Delta b v g A \Delta r g t A$ cells were grown in three independent biological replicates in SS medium and harvested by centrifugation ( $6000 \mathrm{rpm}, 10 \mathrm{~min}, 4^{\circ} \mathrm{C}$ ) at an exponential phase of growth. Total RNA was extracted from pellets using Tri Reagent (Sigma) as recommended by the manufacturer and further treated with DNase I (Sigma) to remove any contaminating genomic DNA. Purified RNA was checked for concentration and integrity using the Bioanalyzer 2100 device (Agilent Technologies). Labeling with Cyanine-5 and Cyanine- 3 was performed as already described (Bibova et al. 2015). For each sample, a Cy5/Cy3 dyeswap technical replicate starting from the same RNA preparation was prepared and hybridized with DNA oligonucleotide probes spotted onto microarray slides for 14 to $16 \mathrm{~h}$ at $52^{\circ} \mathrm{C}$ under agitation. Oligonucleotide probes were designed for 3554 annotated coding sequences of Bordetella pertussis Tohama I strain (BX470248.1, Gl:33591069) and were spotted in duplicate (nonadjacent) on aldehydsilane coated glass slides (Nexterion Slide AL, Schott) using a QArray II spotter (Genetix) equipped with 12 ArrayHit 946MP3 pins. After hybridization, slides were subsequently washed at room temperature in $2 \times$ SSC, $0.2 \%$ SDS for $5 \mathrm{~min}, 0.5 \times$ SSC for $10 \mathrm{~min}, 0.05 \times$ SSC for $5 \mathrm{~min}$, and $0.01 \times$ SSC for 2 min before being dried and scanned using InnopScan700 (Innopsys). Background correction as well as within- and between-array normalization (Yang et al. 2002) was performed from raw data using LIMMA (Linear Models for Microarray Data) $R$ package (Smyth et al. 2003). After normalization, identification of genes with significantly modulated expression was performed using a moderated Student's t-test with empirical Bayes shrinkage of standard errors (Lonnstedt and Britton 2005). Statistics were corrected for multiple testing using a false-discovery rate approach. In order to select genes significantly affected by rgtA deletion, absolute log fold change values $\left(\log _{2} \mathrm{FC}\right)$ of transcript abundance were set to at least 0.5 and threshold for adjusted $P$ value $(P)$ of less than 0.025 was considered as indicative of significance.

\section{Northern blot and primer extension analyses}

For northern blot analysis, $8 \mu \mathrm{g}$ of total RNA was mixed with $2 \times$ RNA loading dye, and heated for $5 \mathrm{~min}$ at $65^{\circ} \mathrm{C}$ before electrophoretic separation on an $8 \%$ polyacrylamide- $8 \mathrm{M}$ urea denaturing gel prepared in $0.5 \times$ TBE buffer. Biotinylated RNAs transcribed in vitro using RNA Century-Plus Marker Template (Invitrogen) served as size markers. The RNA was then transferred onto a Zeta-Probe nylon membrane (Bio-Rad) by electroblotting and UV crosslinked. After blocking with salmon sperm DNA, the membrane was hybridized overnight at $55^{\circ} \mathrm{C}$ with a biotinylated RgtA-specific probe RgtA_NB or after rehybridization with biotinylated SsrA-specific probe SsrA_NB. Signals obtained with SsrA-specific probe detecting tmRNA served as loading controls. Blots were developed using chemiluminescent detection with the 
BrightStar BioDetect kit (Ambion). Hybridization signals were visualized using a G:Box Chemi XRQ device (Syngene).

For primer extension analysis, 20 pmol of RgtA_PE primer were labeled at the $5^{\prime}$ end with $\gamma^{32}$ P-ATP by T4 polynucleotide kinase (Fermentas) as described by the manufacturer and purified with QIAquick Nucleotide Removal Kit (Qiagen). Two picomoles of labeled primer was precipitated with $30 \mu \mathrm{g}$ of RNA, $2.5 \mathrm{vol}$ $100 \%$ ethanol, and 0.1 vol $3 \mathrm{M}$ sodium acetate $(\mathrm{pH} 4.8)$ overnight at $-20^{\circ} \mathrm{C}$. The reaction mixture was centrifuged $(30 \mathrm{~min}, 12,000 \mathrm{~g}$, $4^{\circ} \mathrm{C}$ ) and washed with $70 \%$ ethanol. The pellet was dried, suspended in $12 \mu \mathrm{L}$ RNase-free water and reverse transcribed with Superscript III reverse transcriptase (Invitrogen) according to the manufacturer's recommendations. The sequencing reactions were performed with the fmol DNA Cycle Sequencing System (Promega) using PSK_IGR2735/36 as template and RgtA_PE primer as sequencing primer according to the manufacturer's recommendations. Primer extension and sequencing reaction were separated on a $6 \%$ polyacrylamide- $8 \mathrm{M}$ urea gel. The gel was dried and subjected to autoradiography, and primer extension signals were visualized on Molecular Imager FX Pro Plus (Bio-Rad) instrument.

\section{Western blot analysis}

B. pertussis cells were cultivated in SS medium at $37^{\circ} \mathrm{C}$ and cell pellets from 1-mL aliquots were lysed and boiled in sample buffer. Samples equivalent to $0.1 \mathrm{OD}_{600}$ unit were separated on $12.5 \%$ SDS-PAGE gels and transferred on nitrocellulose membrane. Gels were stained after the transfer to evaluate the transfer efficiency and served also as loading controls. Membranes were blocked with $5 \%$ skim milk and probed with mouse polyclonal antibodies raised against BP3831 followed by incubation with anti-mouse IgG antibodies conjugated with horseradish peroxidase. The antibody-antigen complexes were visualized using SuperSignal West Femto chemiluminescent substrate (Thermo) according to standard protocol on a G:Box Chemi XRQ device (Syngene).

\section{Purification of BP3831 protein and production of anti-BP3831 antibodies}

The gene encoding BP3831 transporter was amplified using forward BP3831 fw and reverse BP3831 rev primers and then cloned into pET42 vector (Novagen) in order to produce N-terminally His-tagged BP3831 protein. The construct was used to transform E. coliBL21 (DE3) strain (Promega) which was then cultivated in LB medium at $37^{\circ} \mathrm{C}$. The production of recombinant $\mathrm{BP} 3831$ protein was induced by $1 \mathrm{mM}$ IPTG at OD $\approx 1.0$ and after $3 \mathrm{~h}$ the cells were harvested by centrifugation $\left(7000 \mathrm{~g}, 20 \mathrm{~min}\right.$ at $\left.4^{\circ} \mathrm{C}\right)$, washed in TS buffer ( $50 \mathrm{mM}$ Tris $\mathrm{pH} 8,300 \mathrm{mM} \mathrm{NaCl}$ ) containing $10 \mathrm{mM}$ EDTA, TS buffer without EDTA and finally resuspended in $30 \mathrm{~mL}$ of TS buffer and lysed by sonication. Inclusion bodies were pelleted $\left(20,000 \mathrm{~g}, 30 \mathrm{~min}\right.$ at $\left.4^{\circ} \mathrm{C}\right)$; pellet was washed by $50 \mathrm{mM}$ Tris $\mathrm{pH}$ 8 containing $4 \mathrm{M}$ urea without resuspension to remove residues of broken cells and then dissolved in TU buffer (50 mM Tris pH 8, $8 \mathrm{M}$ urea). The urea extract was cleared by centrifugation $(20000 \mathrm{~g}$, $30 \mathrm{~min}$ at room temperature) and loaded onto an equilibrated Ni-NTA column (Qiagen). After washing the column with TU buffer, the recombinant protein was eluted by increasing concentra- tions of imidazole $(50-300 \mathrm{mM})$ in TU buffer. The fraction of BP3831 protein eluted by $100 \mathrm{mM}$ imidazole was concentrated and transferred into TU buffer using an Amicon Ultra Centrifugal Filter Unit, 10000 MW cut off size (Merck Millipore). Production of BP3831-specific mouse sera was approved by the Animal Welfare Committee of the Institute of Microbiology of the ASCR, Prague, Czech Republic. A total of $30 \mu \mathrm{g}$ of BP3831 protein in $180 \mu \mathrm{L}$ of PBS was mixed with $20 \mu \mathrm{L}$ of $2 \%$ aluminum hydroxide hydrate (Sigma) and left for $30 \mathrm{~min}$ on ice prior to injection. In total three female 4-wk-old BALB/c mice (Charles Rivers Genetic Models, Inc.) were injected intraperitoneally twice at a 2-wk interval. Mice were bled $14 \mathrm{~d}$ after the last injection for the assessment of anti-BP3831 antibodies.

\section{DATA DEPOSITION}

Microarray data described in this work are available in the Gene Expression Omnibus database under accession number GSE113382.

\section{SUPPLEMENTAL MATERIAL}

Supplemental material is available for this article.

\section{ACKNOWLEDGMENTS}

We gratefully acknowledge Scott Stibitz (FDA, Bethesda, Maryland) for the kind gift of the pSS4245 plasmid and Rudi Antoine (Institute Pasteur, Lille) for stimulating discussions. This work was supported by the Czech Science Foundation (www. gacr.cz) (grant number 16-34825L to B.V.), the Czech Health Research Council (www.azvcr.cz/) (grant number 16-30782A to B.V.), and funding from RVO61388971. This work was also supported by the Ministry of Education, Youth and Sports of the Czech Republic projects (grant numbers CZ.1.07/2.3.00/ 20.0055 to B.V. and I.B., CZ.1.07/2.3.00/30.0003 to B.V. and K.K.). This work was further funded by the Austrian Science Fund (FWF) project SFB F43 to F.A.

Received May 15, 2018; accepted August 1, 2018.

\section{REFERENCES}

Amman F, D'Halluin A, Antoine R, Huot L, Bibova I, Keidel K, Slupek S Bouquet $P$, Coutte L, Caboche $S$, et al. 2018. Primary transcriptome analysis reveals importance of IS elements for the shaping of the transcriptional landscape of Bordetella pertussis. RNA Biol doi: 10.1080/15476286.2018.1462655.

Antal M, Bordeau V, Douchin V, Felden B. 2005. A small bacterial RNA regulates a putative $A B C$ transporter. $J$ Biol Chem 280: 7901-7908.

Bibova I, Skopova K, Masin J, Cerny O, Hot D, Sebo P, Vecerek B. 2013. The RNA chaperone $\mathrm{Hfq}$ is required for virulence of Bordetella pertussis. Infect Immun 81: 4081-4090.

Bibova I, Hot D, Keidel K, Amman F, Slupek S, Cerny O, Gross R, Vecerek B. 2015. Transcriptional profiling of Bordetella pertussis reveals requirement of RNA chaperone Hfq for Type III secretion system functionality. RNA Biol 12: 175-185. 
Bobrovskyy M, Vanderpool CK, Richards GR. 2015. Small RNAs regulate primary and secondary metabolism in gram-negative bacteria. Microbiol Spectr 3 doi: 10.1128/microbiolspec.MBP-0009-2014

Branco Dos Santos F, Olivier BG, Boele J, Smessaert V, De Rop P, Krumpochova P, Klau GW, Giera M, Dehottay P, Teusink B, et al. 2017. Probing the genome-scale metabolic landscape of Bordetella pertussis, the causative agent of whooping cough. Appl Environ Microbiol doi: 10.1128/AEM.01528-17

Brennan RG, Link TM. 2007. Hfq structure, function and ligand binding. Curr Opin Microbiol 10: 125-133.

Burdin N, Handy LK, Plotkin SA. 2017. What is wrong with pertussis vaccine immunity? The problem of waning effectiveness of pertussis vaccines. Cold Spring Harb Perspect Biol 9: a029454.

Carrier MC, Bourassa JS, Masse E. 2017. Cellular homeostasis: a small RNA at the crossroads of iron and photosynthesis. Curr Biol 27: R380-R383.

Chen Q, Ng V, Warfel JM, Merkel TJ, Stibitz S. 2017. Activation of Bvg-repressed genes in Bordetella pertussis by RisA requires cross talk from noncooperonic histidine kinase RisK. J Bacteriol 199: e00475-17.

Cherry JD. 2010. The present and future control of pertussis. Clin Infect Dis 51: 663-667.

Cotter PA, Jones AM. 2003. Phosphorelay control of virulence gene expression in Bordetella. Trends Microbiol 11: 367-373.

Cotter PA, Miller JF. 1994. BvgAS-mediated signal transduction: analysis of phase-locked regulatory mutants of Bordetella bronchiseptica in a rabbit model. Infect Immun 62: 3381-3390.

Coutte L, Huot L, Antoine R, Slupek S, Merkel TJ, Chen Q, Stibitz S, Hot D, Locht C. 2016. The multifaceted RisA regulon of Bordetella pertussis. Sci Rep 6: 32774.

Croinin TO, Grippe VK, Merkel TJ. 2005. Activation of the vrg6 promoter of Bordetella pertussis by RisA. J Bacteriol 187: 1648-1658.

Desnoyers G, Bouchard MP, Masse E. 2013. New insights into small RNA-dependent translational regulation in prokaryotes. Trends Genet 29: 92-98.

Ding Y, Davis BM, Waldor MK. 2004. Hfq is essential for Vibrio cholerae virulence and downregulates $\sigma^{\mathrm{E}}$ expression. Mol Microbiol 53: 345-354.

Geng J, Song Y, Yang L, Feng Y, Qiu Y, Li G, Guo J, Bi Y, Qu Y, Wang W, et al. 2009. Involvement of the post-transcriptional regulator Hfq in Yersinia pestis virulence. PLoS One 4: e6213.

Gottesman S, McCullen CA, Guillier M, Vanderpool CK, Majdalani N, Benhammou J, Thompson KM, FitzGerald PC, Sowa NA, FitzGerald DJ. 2006. Small RNA regulators and the bacterial response to stress. Cold Spring Harb Symp Quant Biol 71: 1-11.

Guillier M, Gottesman S, Storz G. 2006. Modulating the outer membrane with small RNAs. Genes Dev 20: 2338-2348.

Heininger U, Cotter PA, Fescemyer HW, Martinez de Tejada G, Yuk MH, Miller JF, Harvill ET. 2002. Comparative phenotypic analysis of the Bordetella parapertussis isolate chosen for genomic sequencing. Infect Immun 70: 3777-3784.

Hoe CH, Raabe CA, Rozhdestvensky TS, Tang TH. 2013. Bacterial sRNAs: regulation in stress. Int J Med Microbiol 303: 217-229.

Holmqvist E, Wagner EGH. 2017. Impact of bacterial sRNAs in stress responses. Biochem Soc Trans 45: 1203-1212.

Hot D, Slupek S, Wulbrecht B, D'Hondt A, Hubans C, Antoine R, Locht C, Lemoine Y. 2011. Detection of small RNAs in Bordetella pertussis and identification of a novel repeated genetic element. BMC Genomics 12: 207.

Inatsuka CS, Xu Q, Vujkovic-Cvijin I, Wong S, Stibitz S, Miller JF, Cotter PA. 2010. Pertactin is required for Bordetella species to resist neutrophil-mediated clearance. Infect Immun 78: 2901-2909.

Jungnitz H, West NP, Walker MJ, Chhatwal GS, Guzman CA. 1998. A second two-component regulatory system of Bordetella bronchiseptica required for bacterial resistance to oxidative stress, pro- duction of acid phosphatase, and in vivo persistence. Infect Immun 66: 4640-4650.

Karataev GI, Sinyashina LN, Medkova AY, Semin EG, Shevtsova ZV, Matua AZ, Kondzariya IG, Amichba AA, Kubrava DT, Mikvabia ZY. 2016. Insertional inactivation of virulence operon in population of persistent Bordetella pertussis bacteria. Genetika 52: 422-430.

Kasuga T, Nakase Y, Ukishima K, Takatsu K. 1954. Studies on Haemophilis pertussis. III. Some properties of each phase of H. pertussis. Kitasato Arch Exp Med 27: 37-47.

Lacey BW. 1960. Antigenic modulation of Bordetella pertussis. J Hyg. Lond. 58: 57-93.

Locht C. 1999. Molecular aspects of Bordetella pertussis pathogenesis. Int Microbiol 2: 137-144.

Lonnstedt I, Britton T. 2005. Hierarchical Bayes models for cDNA microarray gene expression. Biostatistics 6: 279-291.

Luu LDW, Octavia S, Zhong L, Raftery M, Sintchenko V, Lan R. 2018. Proteomic adaptation of Australian epidemic Bordetella pertussis. Proteomics 18: e1700237.

Mattoo S, Cherry JD. 2005. Molecular pathogenesis, epidemiology, and clinical manifestations of respiratory infections due to Bordetella pertussis and other Bordetella subspecies. Clin Microbiol Rev 18: 326-382.

Melton AR, Weiss AA. 1989. Environmental regulation of expression of virulence determinants in Bordetella pertussis. J Bacteriol 171: 6206-6212.

Merkel TJ, Stibitz S. 1995. Identification of a locus required for the regulation of bvg-repressed genes in Bordetella pertussis. J Bacteriol 177: 2727-2736.

Merkel TJ, Barros C, Stibitz S. 1998. Characterization of the bvgR locus of Bordetella pertussis. J Bacteriol 180: 1682-1690.

Moller T, Franch T, Hojrup P, Keene DR, Bachinger HP, Brennan RG, Valentin-Hansen P. 2002. Hfq: a bacterial Sm-like protein that mediates RNA-RNA interaction. Mol Cell 9: 23-30.

Mooi FR, Van Der Maas NA, De Melker HE. 2014. Pertussis resurgence: waning immunity and pathogen adaptation-two sides of the same coin. Epidemiol Infect 142: 685-694.

Moon K, Bonocora RP, Kim DD, Chen Q, Wade JT, Stibitz S, Hinton DM. 2017. The BvgAS regulon of Bordetella pertussis. MBio 8: e01526-17.

Nakamura MM, Liew SY, Cummings CA, Brinig MM, Dieterich C, Relman DA. 2006. Growth phase- and nutrient limitation-associated transcript abundance regulation in Bordetella pertussis. Infect Immun 74: 5537-5548.

Papenfort K, Vogel J. 2010. Regulatory RNA in bacterial pathogens. Cell Host Microbe 8: 116-127.

Parkhill J, Sebaihia M, Preston A, Murphy LD, Thomson N, Harris DE, Holden MT, Churcher CM, Bentley SD, Mungall KL, et al. 2003. Comparative analysis of the genome sequences of Bordetella pertussis, Bordetella parapertussis and Bordetella bronchiseptica. Nat Genet 35: 32-40.

Raguckas SE, VandenBussche HL, Jacobs C, Klepser ME. 2007. Pertussis resurgence: diagnosis, treatment, prevention, and beyond. Pharmacotherapy 27: 41-52.

Seydlova G, Beranova J, Bibova I, Dienstbier A, Drzmisek J, Masin J, Fiser R, Konopasek I, Vecerek B. 2017. The extent of the temperature-induced membrane remodeling in two closely related Bordetella species reflects their adaptation to diverse environmental niches. J Biol Chem 292: 8048-8058.

Sharma CM, Darfeuille F, Plantinga TH, Vogel J. 2007. A small RNA regulates multiple $A B C$ transporter $m R N A$ s by targeting $C / A$-rich elements inside and upstream of ribosome-binding sites. Genes Dev 21: 2804-2817.

Sittka A, Pfeiffer V, Tedin K, Vogel J. 2007. The RNA chaperone Hfq is essential for the virulence of Salmonella typhimurium. Mol Microbiol 63: 193-217. 
Smirnov A, Wang C, Drewry LL, Vogel J. 2017. Molecular mechanism of mRNA repression in trans by a ProQ-dependent small RNA. EMBO J 36: 1029-1045.

Smyth GK, Yang YH, Speed T. 2003. Statistical issues in cDNA microarray data analysis. Methods Mol Biol 224: 111-136.

Sonnleitner E, Hagens S, Rosenau F, Wilhelm S, Habel A, Jager KE, Blasi U. 2003. Reduced virulence of a hfq mutant of Pseudomonas aeruginosa O1. Microb Pathog 35: 217-228.

Stainer DW, Scholte MJ. 1970. A simple chemically defined medium for the production of phase I Bordetella pertussis. J Gen Microbiol 63: 211-220.

Stenson TH, Allen AG, Al-Meer JA, Maskell D, Peppler MS. 2005. Bordetella pertussis risA, but not risS, is required for maximal expression of Bvg-repressed genes. Infect Immun 73: 5995-6004.

Storz G, Opdyke JA, Zhang A. 2004. Controlling mRNA stability and translation with small, noncoding RNAs. Curr Opin Microbiol 7: 140-144.

Tefon BE, Maass S, Ozcengiz E, Becher D, Hecker M, Ozcengiz G. 2011. A comprehensive analysis of Bordetella pertussis surface proteome and identification of new immunogenic proteins. Vaccine 29: 3583-3595.

Updegrove TB, Zhang A, Storz G. 2016. Hfq: the flexible RNA matchmaker. Curr Opin Microbiol 30: 133-138.

Vogel J, Luisi BF. 2011. Hfq and its constellation of RNA. Nat Rev Microbiol 9: 578-589.

Wagner EG. 2009. Kill the messenger: bacterial antisense RNA promotes mRNA decay. Nat Struct Mol Biol 16: 804-806.

Wagner EG, Romby P. 2015. Small RNAs in bacteria and archaea: who they are, what they do, and how they do it. Adv Genet 90: 133-208.
Wassarman KM. 2002. Small RNAs in bacteria: diverse regulators of gene expression in response to environmental changes. Cell 109: 141-144.

WHO. 2006. Vaccine preventable deaths and the Global Immunization Vision and Strategy, 2006-2015. MMWR Morb Mortal Wkly Rep 55: 511-515.

Williamson YM, Moura H, Whitmon J, Woolfitt AR, Schieltz DM, Rees JC, Guo S, Kirkham H, Bouck D, Ades EW, et al. 2015. A proteomic characterization of Bordetella pertussis clinical isolates associated with a California state pertussis outbreak. Int J Proteomics 2015: 536537.

Wilms I, Moller P, Stock AM, Gurski R, Lai EM, Narberhaus F. 2012. Hfq influences multiple transport systems and virulence in the plant pathogen Agrobacterium tumefaciens. J Bacteriol 194: 52095217.

Wright PR, Georg J, Mann M, Sorescu DA, Richter AS, Lott S, Kleinkauf R, Hess WR, Backofen R. 2014. CopraRNA and IntaRNA: predicting small RNA targets, networks and interaction domains. Nucleic Acids Res 42: W119-W123.

Yang YH, Dudoit S, Luu P, Lin DM, Peng V, Ngai J, Speed TP. 2002. Normalization for cDNA microarray data: a robust composite method addressing single and multiple slide systematic variation. Nucleic Acids Res 30: e15.

Zimna K, Medina E, Jungnitz H, Guzman CA. 2001. Role played by the response regulator Ris in Bordetella bronchiseptica resistance to macrophage killing. FEMS Microbiol Lett 201: 177-180.

Zuker M. 2003. Mfold web server for nucleic acid folding and hybridization prediction. Nucleic Acids Res 31: 3406-3415. 

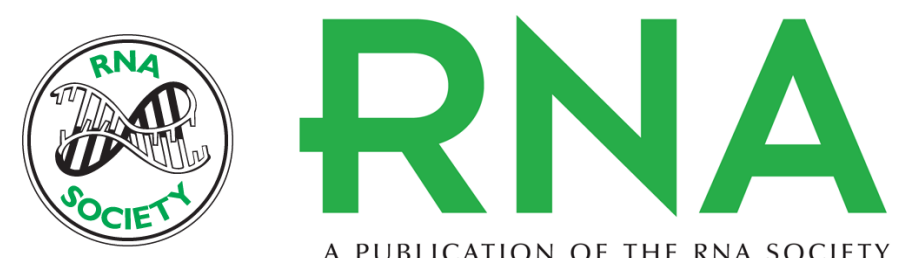

A PUBLICATION OF THE RNA SOCIETY

\section{Signal transduction-dependent small regulatory RNA is involved in glutamate metabolism of the human pathogen Bordetella pertussis}

Kristina Keidel, Fabian Amman, Ilona Bibova, et al.

RNA 2018 24: 1530-1541 originally published online August 10, 2018

Access the most recent version at doi:10.1261/rna.067306.118

\section{Supplemental http://rnajournal.cshlp.org/content/suppl/2018/08/10/rna.067306.118.DC1 \\ Material}

References This article cites 65 articles, 24 of which can be accessed free at: http://rnajournal.cshlp.org/content/24/11/1530.full.html\#ref-list-1

Creative This article is distributed exclusively by the RNA Society for the first 12 months after the Commons

License full-issue publication date (see http://rnajournal.cshlp.org/site/misc/terms.xhtml). After 12 months, it is available under a Creative Commons License (Attribution-NonCommercial 4.0 International), as described at http://creativecommons.org/licenses/by-nc/4.0/.

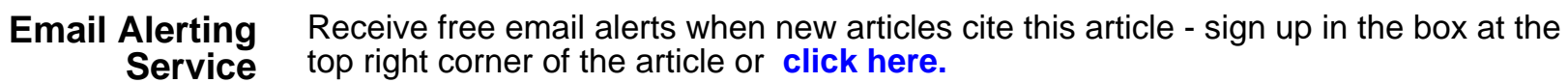

\section{|||||||| Providing Precise Solutions for} your research.

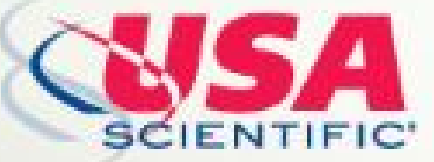

To subscribe to $R N A$ go to:

http://rnajournal.cshlp.org/subscriptions 